\title{
O PROJETO INSTITUCIONAL PIBID-UFFS/2018
}

\author{
Elsio José Corá ${ }^{1}$ \\ Joel Bavaresco ${ }^{2}$
}

\begin{abstract}
RESUMO
O presente texto relata o Programa de Institucional de Bolsas de Iniciação à Docência (PIBID) na Universidade Federal da Fronteira Sul (UFFS) selecionado a partir do edital 07/Capes/2018, no qual a instituição foi contemplada com um número significativo de bolsas e subprojetos/núcleos aprovados. O texto pretende, ainda, servir de registro histórico para o conhecimento de toda a comunidade, principalmente, acadêmica, dos vários desdobramentos, etapas e intencionalidades que perfazem o projeto institucional.
\end{abstract}

Palavras-chave: PIBID. UFFS. INDICADORES. BNCC.

\footnotetext{
${ }^{1}$ Doutor em Filosofia. Professor adjunto da Universidade Federal da Fronteira Sul (UFFS), coordenador do Projeto Institucional PIBID-UFFS - Edital 07/Capes/2018. Contato: cora@uffs.edu.br

2 Especialista em Gerenciamento de projetos, bacharel em Administração Assistente em Administração na Pró-reitoria de Graduação da Universidade Federal da Fronteira Sul (UFFS). Contato: joel.bavaresco@uffs.edu.br
} 


\section{INTRODUÇÃO}

O texto tem a pretensão de colaborar com a premissa de que todo processo formativo deve cooperar para aprimorar as práticas e mobilizar os conhecimentos teóricos acumulados. Para isso, a relação entre as Instituições de Ensino Superior (IES) e as escolas de Educação Básica é Fundamental. Essa aproximação promove a concretização do processo dialético de ação - reflexão - ação com foco na construção de uma nova identidade docente e ressignifica, por seu turno, o percurso formativo inicial, uma vez que, por meio da vivência em sala de aula, já nos primeiros semestres do curso, é possível conhecer os desafios da profissão bem como a necessidade de uma formação imbricada com e a partir do contexto escolar.

Ainda, é importante enfatizar o quanto o Programa Institucional de Bolsas de Iniciação à Docência (PIBID) tem contribuído para o fortalecimento dos cursos de formação de professores, no sentido de promover experiências que possibilitam, a partir dos diálogos propiciados pelo Programa, redesenhar os cursos de licenciatura das IES.

Por fim, nesses últimos anos, o PIBID fortaleceu sua identidade, tanto nas IES quanto nas escolas de Educação Básica, tornando-se uma importante referência. Assim, é essencial destacar a importância do Programa, por meio de suas ações, na contribuição para elevação da qualidade da formação de professores, na melhoria da sua futura atuação nas escolas e, principalmente, por se tratar de uma demanda histórica para a construção da educação pública no País.

Sendo assim, este texto procura - como forma de registro histórico e para conhecimento de toda a comunidade, principalmente, acadêmica -apresentar o projeto institucional PIBID-UFFS/2018, enviado e selecionado no edital 07/Capes/2018. 


\section{O PROJETO INSTITUCIONAL PIBID-UFFS/2018}

O Projeto Institucional PIBID-UFFS possui como objetivo principal inserir os acadêmicos nas escolas da rede pública municipal e estadual nos três estados da Região Sul, com vistas a elevar a qualidade das ações acadêmicas voltadas à formação dos professores, oportunizando aos estudantes vivenciar o cotidiano das escolas e promovendo a integração entre a Educação Superior e Educação Básica bem como fortalecer a escola pública como espaço legítimo de formação de professores, tendo como fio condutor a Base Nacional Comum Curricular (BNCC), Diretrizes Curriculares Nacionais (DCNs), Projetos Pedagógicos dos Cursos (PPCs) dos cursos de licenciatura da Universidade Federal da Fronteira Sul (UFFS) e a política institucional de formação de professores (UNIVERSIDADE FEDERAL DA FRONTEIRA SUL, 2017).

Possui, ainda, como objetivos específicos: a) promover a integração entre Educação Superior e Educação Básica, no intuito de sensibilizar para o trabalho docente; b) propiciar a articulação entre teoria e prática necessárias à formação dos docentes, elevando a qualidade das ações acadêmicas nos cursos de licenciatura da UFFS; c) aproximar os licenciandos do território escolar e das vivências do cotidiano da escola, proporcionando-lhes oportunidades de fortalecimento da identidade docente e do pertencimento a realidade escolar; d) oportunizar maior participação em experiências metodológicas, tecnológicas e práticas docentes de caráter inovador e interdisciplinar que busquem a superação de problemas identificados no processo de ensino-aprendizagem; e) proporcionar uma formação humana integral dentro do percurso formativo nos cursos de licenciaturas da UFFS; f) contribuir para a construção da identidade e da unidade multicampi dos cursos de licenciatura da UFFS, respeitando as especificidades locais e das áreas do conhecimento. 


\section{A ARTICULAÇÃO ENTRE OS SUBPROJETOS E O PROJETO INSTITUCIONAL}

As diferentes áreas dos subprojetos buscam a articulação das licenciaturas da UFFS, promovendo a integração entre os cursos do mesmo campus e de diferentes campi. É objetivo institucional o fortalecimento e a consolidação das licenciaturas e a aproximação, principalmente no período de formação do profissional-professor, com a sala de aula e o ambiente escolar.

Sendo assim, a inserção, as vivências de docência e os compromissos com a formação de professores e com a Educação Básica reafirmam a missão da UFFS, bem como os PPCs de licenciatura da instituição, os quais explicitam compromissos com a relação teoria e prática, a interdisciplinaridade, a formação social e cultural e o desenvolvimento das habilidades e competências necessárias ao exercício da docência como prática e compromisso social, ancorada na pesquisa e na extensão como ferramentas na formação dos cursos de licenciatura, articulados com a Educação Básica pública e outros espaços educativos escolares e não escolares.

Esse contexto encontra-se em um plano que caracteriza o esforço institucional que, embora recente, vem sendo construído pela comunidade acadêmica dessa instituição, revelado a partir da escuta e observação das necessidades, anseios, angústias e tensões da comunidade local e regional inerente aos três estados do Sul. Esse diálogo proporcionou a elaboração de uma Política Institucional para Formação Inicial e Continuada de Professores da Educação Básica, a partir da implementação do Fórum das Licenciaturas da UFFS.

Nessa perspectiva, os movimentos internos terão a participação efetiva dos estudantes no planejamento escolar, na avaliação, em reuniões pedagógicas, dentre outros exercícios construídos na interlocução em curso. Os movimentos externos dar-se-ão em estudos sistemáticos com a presença dos professores 
coordenadores de área, supervisores, coordenador institucional, bem como dos estudantes com o objetivo de refletir e produzir alternativas de interlocução mobilizadoras da melhoria do processo ensino-aprendizagem.

Esse projeto constitui-se num exercício de reflexão teórico-prática dinamizador de novos protagonismos de atitudes investigativas e interventivas, expressas no conjunto das intenções da Coordenação de Aperfeiçoamento de Pessoal de Nível Superior (Capes), materializadas em sua política de fomento para Educação Básica, por meio do PIBID, Residência Pedagógica, entre outros projetos e programas e a missão da UFFS na sua ênfase e fomento em cursos de licenciatura.

\section{PIBID, PRÁTICAS COMO COMPONENTE CURRICULAR E AS ATIVIDADES TEÓRICO-PRÁTICAS DOS CURSOS DE LICENCIATURA}

A indissociabilidade entre teoria e prática orientará toda organização e desenvolvimento curricular dos cursos de licenciatura, de forma que as dimensões conceituais, contextuais e pedagógicas estejam integradas no ato educativo. Assim, em consonância com Resolução CNE/CP n. 2, de $1^{\circ}$ de julho de 2015, que define as Diretrizes Curriculares Nacionais para a Formação Inicial e Continuada em Nível Superior de Profissionais do Magistério para a Educação Básica, fica estabelecida, para fins de organização da prática no âmbito dos cursos de licenciatura, a diferenciação entre a prática e a prática como componente curricular. Nesse sentido, a prática compreendida como momento complementar à formação teórica, em que são desenvolvidas atividades voltadas para a formação de habilidades específicas.

No âmbito da UFFS, de acordo com a Resolução n. 4/CONSUNI CGRAD/UFFS/2014, que aprova o Regulamento de Graduação, tais práticas são definidas curricularmente como aquelas 
em que os estudantes, sob orientação e supervisão de docente, realizam ou observam a realização de ensaios, experimentos e procedimentos descritos no protocolo de aula prática, em laboratório, em campo, em ambiente de exercício profissional ou outro ambiente preparado para tal.

Sendo assim, o PIBID-UFFS compreende a prática como componente curricular, focada na formação para a docência, em que se articulam, de forma explícita, dimensões conceituais, contextuais e pedagógicas para o desenvolvimento de habilidades docentes, materializadas em cada subprojeto/núcleo que se articulam num todo ordenado. Assim, a organização das atividades nos subprojetos poderá ser feita por meio de componentes desenvolvidos vinculados aos eixos que estruturam a prática como componente curricular, envolvendo o currículo escolar e seu desenvolvimento, a gestão da educação e a produção e difusão do conhecimento, fortalecendo o vínculo da iniciação à docência do futuro profissional da educação.

\section{A INSTITUCIONALIZAÇÃO DA INICIAÇÃO À DOCÊNCIA NA UFFS}

O PIBID-UFFS insere-se como estratégia de incentivo aos estudantes de licenciatura a aderirem de modo efetivo à Educação Básica, propondo-lhes desafios teórico-práticos e vivências na escola, a partir de sua formação específica. Além disso, visa a contribuir para valorização do magistério, promovendo intercâmbio de ideias e de criação de novos métodos de ensino-aprendizagem entre a formação superior e a iniciação à docência na Educação Básica.

Outrossim, é inegável a contribuição dos professores das redes de Educação Básica na formação de nossos estudantes. Entende-se que não é mais possível pensar a formação de professores, no 
nível superior, sem associar uma vivência intencional e rotineira no âmbito da sala de aula em que, futuramente, desenvolverão sua profissão. Por outro lado, o PIBID torna-se uma excelente oportunidade para que os cursos se consolidem dentro da Política Nacional de Formação de Professores e na implementação da BNCC.

Outro ponto importante na definição das estratégias institucionais para a iniciação à docência foi a elaboração de indicadores, propostos para o acompanhamento e o monitoramento do Programa, bem como das atividades e ações institucionais. Eles nos permitem alcançar maior proximidade no processo de implementação do Programa, a nível institucional e multicampi. São eles:

Quadro 1 - Indicadores do Projeto

\begin{tabular}{|l|l|l|}
\hline Indicador & Descritor & Resultados esperados \\
\hline $\begin{array}{l}\text { Participação } \\
\text { nas atividades } \\
\text { previstas } \\
\text { no projeto } \\
\text { institucional. }\end{array}$ & $\begin{array}{l}\text { Os estudantes colaborarão } \\
\text { nas atividades previstas } \\
\text { em conjunto com os } \\
\text { coordenadores de área e } \\
\text { professores supervisores, } \\
\text { nos diferentes espaços } \\
\text { escolares. }\end{array}$ & $\begin{array}{l}\text { Desenvolver, planejar } \\
\text { e executar atividades } \\
\text { pedagógicas nos diferentes } \\
\text { espaços escolares (salas de } \\
\text { aula, laboratórios, espaços } \\
\text { recreativos desportivos, } \\
\text { ateliês e secretarias), } \\
\text { vivenciando a realidade } \\
\text { escolar e seu território. }\end{array}$ \\
\hline $\begin{array}{l}\text { Relação das } \\
\text { atividades } \\
\text { desenvolvidas } \\
\text { nos subprojetos } \\
\text { com a BNCC. }\end{array}$ & $\begin{array}{l}\text { Os estudantes, a partir } \\
\text { da orientação do } \\
\text { coordenador de área e do } \\
\text { supervisor, elaborarão } \\
\text { as atividades com vistas } \\
\text { ao desenvolvimento de } \\
\text { habilidades e competências } \\
\text { de acordo com os objetos } \\
\text { de cada disciplina prevista } \\
\text { na BNCC. }\end{array}$ & $\begin{array}{l}\text { Compreender os objetivos } \\
\text { e direitos de aprendizagem } \\
\text { presentes em cada } \\
\text { disciplina, bem como sua } \\
\text { estrutura organizacional } \\
\text { e mudanças ocorridas a } \\
\text { partir da implementação } \\
\text { da BNCC no currículo } \\
\text { específico e da escola. }\end{array}$ \\
\hline
\end{tabular}




\begin{tabular}{|c|c|c|}
\hline Indicador & Descritor & Resultados esperados \\
\hline $\begin{array}{l}\text { Estudo do } \\
\text { contexto } \\
\text { educacional e do } \\
\text { território. }\end{array}$ & $\begin{array}{l}\text { Análise dos documentos } \\
\text { que orientam as ações } \\
\text { da escola, participação } \\
\text { e acompanhamento das } \\
\text { instâncias colegiadas } \\
\text { da escola, realização } \\
\text { de diagnóstico, da } \\
\text { comunidade escolar e seu } \\
\text { entorno. }\end{array}$ & $\begin{array}{l}\text { Compreender o contexto } \\
\text { escolar em que serão } \\
\text { realizadas as atividades } \\
\text { dos subprojetos, no } \\
\text { intuito de vivenciar } \\
\text { o contexto teórico- } \\
\text { prático, aproximando } \\
\text { os conhecimentos } \\
\text { historicamente produzidos } \\
\text { e sua efetivação no } \\
\text { ambiente e na dinâmica da } \\
\text { sala de aula, despertando } \\
\text { a identidade para a } \\
\text { docência. }\end{array}$ \\
\hline $\begin{array}{l}\text { Apoio à política } \\
\text { pública de } \\
\text { alfabetização e } \\
\text { letramento. }\end{array}$ & $\begin{array}{l}\text { Os subprojetos ofertarão } \\
\text { oficinas e minicursos } \\
\text { de leitura e produção } \\
\text { de textos, bem como } \\
\text { organizarão grupo de } \\
\text { estudos de fundamentos } \\
\text { teórico metodológicos } \\
\text { sobre as temáticas } \\
\text { relacionadas à docência, } \\
\text { entre outros. }\end{array}$ & $\begin{array}{l}\text { Fortalecer e apoiar as } \\
\text { escolas no processo de } \\
\text { alfabetização e letramento } \\
\text { dos estudantes, com } \\
\text { vistas a oferecer suporte } \\
\text { didático-pedagógico aos } \\
\text { professores supervisores } \\
\text { e aos pibidianos, para que } \\
\text { estes possam contribuir } \\
\text { para a efetivação dos } \\
\text { direitos de aprendizagem } \\
\text { dos alunos. }\end{array}$ \\
\hline $\begin{array}{l}\text { Produção, } \\
\text { apresentação } \\
\text { e discussão } \\
\text { de materiais } \\
\text { didático- } \\
\text { pedagógicos } \\
\text { relacionados à } \\
\text { BNCC. }\end{array}$ & $\begin{array}{l}\text { Os bolsistas, juntamente } \\
\text { com os supervisores e } \\
\text { coordenadores de área, } \\
\text { irão escolher, apresentar } \\
\text { e discutir materiais } \\
\text { didático-pedagógicos } \\
\text { com intuito de mediar o } \\
\text { ensino das habilidades e } \\
\text { competências previstas } \\
\text { na BNCC, com vistas ao } \\
\text { estímulo à inovação, à ética } \\
\text { profissional, à criatividade, } \\
\text { à inventividade e à } \\
\text { interação dos pares. }\end{array}$ & $\begin{array}{l}\text { Espera-se, a partir } \\
\text { do desenvolvimento } \\
\text { das ações didático- } \\
\text { pedagógicas no contexto } \\
\text { da escola, a saber: salas } \\
\text { de aula, laboratórios, } \\
\text { bibliotecas, entre outros, } \\
\text { ampliar a articulação com } \\
\text { a comunidade escolar, } \\
\text { fortalecendo o processo } \\
\text { de ensino-aprendizagem } \\
\text { e os conhecimentos } \\
\text { necessários previstos na } \\
\text { BNCC. }\end{array}$ \\
\hline
\end{tabular}




\begin{tabular}{|c|c|c|}
\hline Indicador & Descritor & Resultados esperados \\
\hline $\begin{array}{l}\text { Monitoramento } \\
\text { e avaliação } \\
\text { das atividades } \\
\text { previstas nos } \\
\text { subprojetos. }\end{array}$ & $\begin{array}{l}\text { A instituição acompanhará } \\
\text { o desenvolvimento das } \\
\text { atividades realizadas pelos } \\
\text { subprojetos por meio } \\
\text { de encontros periódicos } \\
\text { com os coordenadores } \\
\text { de área, professores } \\
\text { supervisores e bolsistas } \\
\text { de iniciação à docência. } \\
\text { Além disso, objetiva- } \\
\text { se o desenvolvimento } \\
\text { de um software para } \\
\text { monitoramento e avaliação } \\
\text { do PIBID-UFFS a } \\
\text { partir dos indicadores e } \\
\text { princípios do PIBID/Capes. }\end{array}$ & $\begin{array}{l}\text { Avaliar e monitorar } \\
\text { o processo de } \\
\text { desenvolvimento e } \\
\text { realização das atividades } \\
\text { previstas no projeto } \\
\text { institucional e nos } \\
\text { subprojetos, no intuito de } \\
\text { garantir a concretização } \\
\text { dos objetivos propostos } \\
\text { e a plena realização do } \\
\text { Programa. }\end{array}$ \\
\hline $\begin{array}{l}\text { Formação } \\
\text { continuada } \\
\text { de professores } \\
\text { das escolas da } \\
\text { rede de ensino } \\
\text { vinculadas ao } \\
\text { PIBID }\end{array}$ & $\begin{array}{l}\text { Elaboração da estrutura } \\
\text { curricular de um curso de } \\
\text { aperfeiçoamento, tendo } \\
\text { como base o tema "BNCC } \\
\text { e sua implementação no } \\
\text { currículo das disciplinas } \\
\text { vinculadas às escolas, } \\
\text { a partir dos cursos } \\
\text { contempladas pelos } \\
\text { subprojetos do PIBID- } \\
\text { UFFS". }\end{array}$ & $\begin{array}{l}\text { Adequação do currículo } \\
\text { escolar à BNCC; Maior } \\
\text { aderência nos cursos de } \\
\text { licenciatura da UFFS } \\
\text { à proposta curricular } \\
\text { referenciada pela BNCC; } \\
\text { Contribuir no processo } \\
\text { de formação continuada } \\
\text { da comunidade escolar } \\
\text { receptora do PIBID; } \\
\text { Vincular o acadêmico } \\
\text { bolsista na dinâmica } \\
\text { da escola, a partir da } \\
\text { referência curricular } \\
\text { proposta pela BNCC. }\end{array}$ \\
\hline
\end{tabular}

Fonte: UFFS (2018)

\section{SELEÇÃO DOS DISCENTES E PROFESSORES SUPERVISORES}

A seleção dos discentes bolsistas e professores supervisores, ocorre a partir de processos seletivos promovidos pela $\mathrm{PRO}$ GRAD/UFFS, por meio de editais específicos, com base no que 
preconiza o Edital n. 7/2018/Capes. O processo seletivo para os discentes é realizado em três etapas, cujas duas últimas são pontuadas: entrega da documentação de inscrição, análise da carta de intenções apresentada pelos discentes e entrevista. O processo seletivo para os professores supervisores é formado por entrevista, análise do currículo e da carta de intenções e possui como requisitos principais estar em efetivo exercício em escola habilitada para receber o PIBID e ter formação compatível com a área de atuação no Programa.

O controle de assiduidade e acompanhamento das atividades nos subprojetos é desenvolvido por meio de fichas de frequência e acompanhamento, e posteriormente pretendemos desenvolver, em conjunto com o setor de tecnologia da informação da UFFS, um software de monitoramento e avaliação, a partir dos indicadores e dos princípios do PIBID.

\section{SUBPROJETOS E NÚCLEOS SELECIONADOS NO PIBID-UFFS/2018}

A UFFS, a partir do Edital n. 7/2018/Capes, aprovou em seu projeto institucional (PIBID-UFFS) 11 subprojetos, que são as áreas do conhecimento que integram componentes curriculares da Educação Básica. Cada subprojeto é dividido em núcleos, sendo que há um total de 21 núcleos de iniciação à docência organizados no âmbito dos cinco campi que possuem licenciaturas (Cerro Largo, Chapecó, Erechim, Laranjeiras do Sul e Realeza). O núcleo é composto de um coordenador de área, três professores supervisores que atuam na escola e até 30 discentes ( 24 bolsistas e seis voluntários).

Os municípios beneficiados com as atividades do PIBID da UFFS são: Capanema/PR, Cerro Largo/RS, Chapecó/SC, Erechim/ RS, Laranjeiras do Sul/PR, Planalto/PR, Quedas do Iguaçu/PR, 
Realeza/PR, Rio Bonito do Iguaçu/PR, Salvador das Missões/RS e Santa Izabel do Oeste/PR. Trata-se de um projeto de abrangência interestadual, que contribuiu/contribui sobremaneira para o desenvolvimento das licenciaturas dessa grande região e, por consequência, da melhoria da qualidade da Educação Básica.

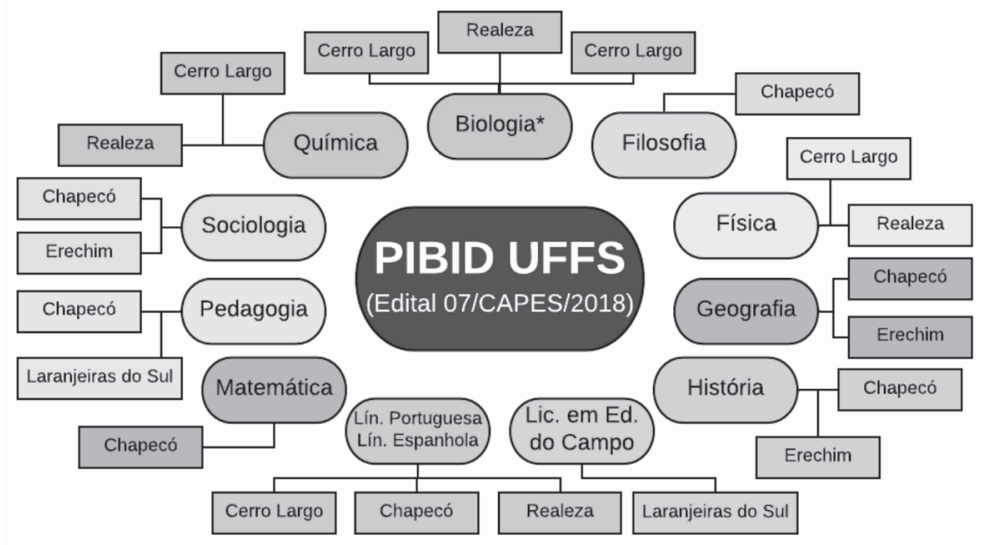

Figura 1 - Subprojetos e núcleos do PIBID-UFFS/2018 Fonte: UFFS (2018)

Conforme já indicado, além do coordenador institucional, cada núcleo de iniciação à docência do PIBID/UFFS-2018 é formado por um coordenador de área bolsista (ao menos um voluntário) responsáveis por acompanhar três professores supervisores e até 30 discentes, sendo 24 bolsistas. Cada professor supervisor atua com de oito a dez alunos de iniciação à docência. Essa composição resulta no quadro de pessoal a seguir: 
Tabela 1 - Composição de pessoal do PIBID/UFFS-2018

\begin{tabular}{lcccc}
\hline \multicolumn{5}{c}{ Estatísticas PIBID por campus } \\
\hline Modalidade & $\begin{array}{c}\text { Cerro } \\
\text { Largo }\end{array}$ & Chapecó & Erechim & $\begin{array}{c}\text { Laranjeiras } \\
\text { do Sul }\end{array}$ \\
\hline Coord. de área bolsista & 5 & 7 & 3 & 2 \\
\hline Coord. de área voluntário & 6 & 9 & 3 & 2 \\
\hline Prof. Supervisor & 15 & 21 & 9 & 6 \\
\hline Iniciação à docência (ID) & 120 & 168 & 72 & 48 \\
\hline ID Voluntário* & 30 & 39 & 18 & 12 \\
\hline TOTAIS & $\mathbf{1 7 6}$ & $\mathbf{2 4 4}$ & $\mathbf{1 0 5}$ & $\mathbf{7 0}$ \\
\hline
\end{tabular}

Fonte: UFFS (2018)

Nota: A cota de voluntários não foi preenchida em sua integralidade em alguns dos núcleos de ID, apesar de terem sido realizadas diversas seleções.

Observa-se que no total, o PIBID-UFFS/2018 envolve um contingente de 739 pessoas, sendo 504 alunos bolsistas, 123 alunos voluntários, 63 professores supervisores da Educação Básica, 21 coordenadores de área bolsistas e 27 voluntários, além do coordenador institucional. Trinta e cinco escolas da região de abrangência da UFFS recebem atividades do Programa e o repasse, em bolsas, ultrapassa o montante de $\mathrm{R} \$ 5$ milhões de reais.

\section{CONSIDERAÇÕES FINAIS}

No contexto atual, ao discutir a formação de professores, é imperativo falar sobre o debate público que se tem em torno da construção da BNCC, que atende ao disposto no Plano Nacional de Educação (PNE), aprovado por meio da Lei n. 13.005, de 25 de junho de 2014, que estabeleceu prazo para elaboração de proposta de direitos e objetivos de aprendizagem e desenvolvimento que configurarão a BNCC.

Entretanto, a discussão acerca dessa temática não é recente. O artigo 210 da Constituição Federal, promulgada em 1988, 
determina que "Serão fixados conteúdos mínimos para o Ensino Fundamental, de maneira a assegurar formação básica comum e respeito aos valores culturais e artísticos, nacionais e regionais". (BRASIL, 1988).

Em 1996, foi aprovada a Lei de Diretrizes e Bases da Educação Nacional, importante marco da Educação Brasileira, na qual, em seu artigo 26, aparece o termo BNC: "Os currículos da educação infantil, do ensino fundamental e do ensino médio devem ter base nacional comum [...]" (BRASIL, 1996). Desde então, foram produzidos, no País, diversos documentos com objetivo de contribuir para a construção de currículos nas escolas de Educação Básica.

É importante dizer que além dos marcos legais citados, a construção de orientações curriculares é relevante à medida que contribui para indicar caminhos para o incremento da educação pública no Brasil, como pode ser percebidos nos documentos finais da Conferência Nacional de Educação (CONAE) em 2010: "Indicação das bases epistemológicas que garantam a configuração de um currículo que contemple, ao mesmo tempo, uma base nacional demandada pelo sistema nacional de educação e as especificidades regionais e locais." (BRASIL, 2010, p. 38).

Ou de maneira mais explícita na CONAE de 2014:

Elaborar, mediante consulta pública nacional, a proposta de direitos e objetivos de aprendizagem e desenvolvimento para os alunos do ensino fundamental e médio, nas diversas modalidades a serem atingidas nos tempos e etapas de organização destes níveis de ensino, com vistas a garantir formação básica comum, garantindo assistência técnica e financeira. (BRASIL, 2014a, p. 71).

As questões apontadas reforçam a necessidade trazida pelo Edital n. 7/Capes/2018 para a contrapartida institucional para implementação da BNCC no currículo dos cursos de graduação de cada IES. 
Acredita-se que isso será possível a partir do diálogo com professores, estudantes e gestores da Educação Básica e do Ensino Superior; associações científicas; bem como representantes de instituições e organizações da sociedade civil que trabalham e/ou se preocupam com as questões educacionais. O "trabalho coletivo" para a construção da BNCC foi fundamental para a garantia do direito à educação expresso na legislação educacional brasileira e legitimado a partir de instâncias importantes para o debate público, como citado anteriormente, nas CONAEs realizadas em 2010 e 2014.

Entretanto, as reviravoltas políticas no cenário nacional em meio à elaboração do documento final da BNCC também atingiram a própria definição daquilo que se esperava de um documento tão significativo como a BNCC. Esse resultado final, depois de todas as mudanças operacionalizadas na nova gestão do Ministério da Educação (MEC), pode ser visualizado por meio das dez competências gerais da BNCC, que supostamente "ampliam" os direitos e objetivos de aprendizagem, bem como os eixos ético, político e estético das Diretrizes Curriculares Nacionais para a Educação Básica.

Assim, o trabalho que vem sendo desenvolvido na região de abrangência da UFFS, principalmente por meio do PIBID e de outros programas federais e institucionais é de auxiliar estados, municípios e escolas na construção e implementação do seu currículo, a partir do referencial definido pela BNCC.

\section{REFERÊNCIAS}

BRASIL. Conferência Nacional de Educação: documento final. Brasília, DF, 2010. Disponível em: http://conae.mec.gov.br/images/ stories/pdf/pdf/documetos/documento_final_sl.pdf. Acesso em: 20 nov. 2018. 
BRASIL. Constituição (1988). Constituição da República Federativa do Brasil. Brasília, DF, 1988. Disponível em: http://www.planalto.gov. br/ccivil_03/constituicao/constituicao.htm. Acesso em: 20 mar. 2019

BRASIL. Lei n. 9.394, de 20 de dezembro de 1996. Estabelece as diretrizes e bases da educação nacional. Brasília, DF, 1996. Disponível em: http://www.planalto.gov.br/ccivil_03/leis/L9394.htm. Acesso em: 12 dez. 2018.

BRASIL. Ministério da Educação. Conferência Nacional de Educação. O PNE na Articulação do Sistema Nacional de Educação: participação popular, cooperação federativa e regime de colaboração - Documento Final. Brasília, DF, 2014a. Disponível em: http://conae2014.mec.gov.br/ images/doc/Sistematizacao/DocumentoFinal29012015.pdf. Acesso em: 20 jun. 2018.

BRASIL. Ministério da Educação. Instituto Nacional de Estudos e Pesquisas Educacionais Anísio Teixeira. Censo Escolar da Educação Básica 2013 - Resumo Técnico. Brasília, DF, 2014b. Disponível em: http://download.inep.gov.br/educacao_basica/censo_escolar/resumos_ tecnicos/resumo_tecnico_censo_educacao_basica_2013.pdf. Acesso em: 20 jun. 2016.

BRASIL. Ministério da Educação. Conselho Nacional de Educação. Resolução CNE/CP no 02, de $1^{\circ}$ de julho de 2015. Define as Diretrizes Curriculares Nacionais para a formação inicial em nível superior (cursos de licenciatura, cursos de formação pedagógica para graduados e cursos de segunda licenciatura) e para a formação continuada. Brasília, DF, 2015. Disponível em http://portal.mec.gov. br/docman/agosto-2017-pdf/70431-res-cne-cp-002-03072015-pdf/file. Acesso em: 14 maio 2019.

BRASIL. Ministério da Educação. Base Nacional Comum Curricular. Portal virtual. 2018. Disponível em: http://basenacionalcomum.mec. gov.br. Acesso em: 13 set. 2018.

COORDENAÇÃO DE APERFEIÇOAMENTO DE PESSOAL DE NÍVEL SUPERIOR (Capes). Edital n. 07/2018-Capes. Brasília, DF, 2018. Disponível em: https://www.capes.gov.br/educacao-basica/ capespibid/editais-e-selecoes. Acesso em: 2 maio 2019. 
UNIVERSIDADE FEDERAL DA FRONTEIIRA SUL (UFFS). PIBID Programa Institucional de Bolsa de Iniciação à Docência. 2018. Não publicado.

UNIVERSIDADE FEDERAL DA FRONTEIRA SUL (UFFS). Resolução n. 04/CONSUNI CGRAD/UFFS/2014. Aprova o Regulamento da Graduação da Universidade Federal da Fronteira Sul. 2014. Disponível em: https://www.uffs.edu.br/atos-normativos/ resolucao/consunicgrad/2014-0004. Acesso em: 4 maio 2019.

UNIVERSIDADE FEDERAL DA FRONTEIRA SUL (UFFS). Resolução n. 02/CONSUNI-CGAE/UFFS/2017. Aprova a Política Institucional da UFFS para Formação Inicial e Continuada de Professores da Educação Básica. 2017. Disponível em: https://www. uffs.edu.br/atos-normativos/resolucao/consunicgae/2017-0002. Acesso em: 10 maio 2019.

UNIVERSIDADE FEDERAL DA FRONTEIRA SUL (UFFS). Resolução n. 04/CONSUNI CGAE/UFFS/2017. Aprova a criação do Fórum das Licenciaturas da Universidade Federal da Fronteira Sul. 2017. Disponível em: https://www.uffs.edu.br/atos-normativos/ resolucao/consunicgae/2017-0004. Acesso em: 14 maio 2019. 